Artigo original

Hegemonia - Revista Eletrônica do Programa de Mestrado em Direitos Humanos, Cidadania e Violência/Ciência Política do Centro Universitário Unieuro

ISSN: $1809-1261$

UNIEURO, Brasília, número 23, Janeiro a Junho de 2018, pp. 27-54.

Recebido em: 19/10/2017

Avaliado em: 9/11/2017

Aprovado em: 30/11/2017

\title{
UN ANÁLISIS COMPARATIVO DE LA CALIDAD DE LA DEMOCRACIA EN BRASIL Y PERÚ:
} Testando procedimientos, contenidos y resultados

Carlos Ugo Santander Joo y Carlos F. Domínguez Avila ${ }^{2}$

RESUMEN: El presente artículo compara la evolución reciente, los actores, las dimensiones, y las perspectivas de los regímenes democráticos existentes en Brasil y Perú, principalmente entre 2015 y 2017. En términos teórico-metodológicos, el presente trabajo utiliza como variables de comparación las dimensiones y subdimensiones propuestas por Leonardo Morlino para el estudio de la calidad de la democracia. En términos empíricos, los datos recolectados sobre ambos países son los más recientes, fidedignos y equivalentes posibles; todo ello con el propósito de realizar un ejercicio comparativo que sea confiable y consistente, además de avanzar en una agenda ampliada de pesquisa.

PALABRAS-LLAVE: Brasil; Perú; Calidad de la Democracia; Sistema político; Sociedad civil; Análisis comparativo.

ABSTRACT: The paper compares the recent evolution, the actors, the dimensions, and the future perspectives of the ongoing democratic regimes of Brazil and Peru, particularly between 2015 and 2017. In theoretical and methodological terms, the paper uses as comparative variables the dimensions of the Leonardo Molino's approach to the study and research on the quality of democracy. In empirical terms, the collected data about both countries is the most equivalent and recent. We aim to make a comparative analysis, and propose to advance in a deeper and amplificated research agenda.

${ }^{1}$ Doutor em Ciências Sociais e docente da Universidade Federal de Goiás.

${ }^{2}$ Doutor em História e Pós-doutorado em Ciência Política, e docente do Centro Universitário Unieuro. 
Artigo original

Hegemonia - Revista Eletrônica do Programa de Mestrado em Direitos Humanos, Cidadania e Violência/Ciência Política do Centro Universitário Unieuro

ISSN: $1809-1261$

UNIEURO, Brasília, número 23, Janeiro a Junho de 2018, pp. 27-54.

KEY-WORDS: Brazil; Peru; Quality of Democracy; Political System; Civil Society; Comparative analysis.

RESUMO: O presente artigo compara a evolução recente, os atores, as dimensões, e as perspectivas dos regimes democráticos existentes no Brasil e no Peru, principalmente entre 2015 y 2017. Em termos teórico-metodológicos, o texto utiliza como variáveis de comparação às dimensões propostas pelo cientista político italiano Leonardo Morlino para o estudo e a pesquisa da qualidade da democracia. Em termos empíricos, os dados coletados sobre ambos os países são os mais recentes, fidedignos e equivalentes possível; isso com o propósito de realizar um exercício de análise comparativa, e avançar uma agenda abrangente de pesquisa.

PALAVRAS-CHAVE: Brasil; Peru; Qualidade da Democracia; Sistema Político; Sociedade Civil; Análise comparativa.

\section{Introducción}

El propósito del presente artículo es analizar comparativamente la calidad de la democracia existente en Brasil y en Perú. En consecuencia, es pertinente iniciar el análisis reconociendo la ponderación básica del politólogo italiano Leonardo Morlino (2016) en el sentido de que una 'buena' democracia o una democracia de calidad es, en primer lugar, un régimen legitimado y estable, donde los ciudadanos están satisfechos, ya que los gobernantes electos son capaces y están dispuestos - por la vía institucional - a atender sus necesidades y demandas (calidad de resultados); en segundo lugar, las comunidades y los ciudadanos disfrutan de libertad, ciudadanía, derechos humanos e igualdad/solidaridad más allá del mínimo vital (calidad de contenido); y en tercer lugar los ciudadanos de una democracia de calidad deben estar capacitados para monitorear y evaluar a través de elecciones - o indirectamente, por otros mecanismos e instancias - el desarrollo de las actividades del Estado y el predominio de la Ley.

En ese mismo sentido, es pertinente mencionar que el modelo analítico de Morlino se desdobla en ocho dimensiones, que posibilitan la realización de los estudios de caso y comparativos. Las primeras cinco dimensiones son de naturaleza procesual: (1) el Estado de Derecho, (2) la Rendición de Cuentas Electoral, (3) la Rendición de Cuentas 
Artigo original

Hegemonia - Revista Eletrônica do Programa de Mestrado em Direitos Humanos, Cidadania e Violência/Ciência Política do Centro Universitário Unieuro

ISSN: $1809-1261$

UNIEURO, Brasília, número 23, Janeiro a Junho de 2018, pp. 27-54.

Interinstitucional, (4) la Participación Política, y (5) la Competencia Política. Dos dimensiones de naturaleza substancial o de contenido: (6) las Libertades, y (7) la Solidaridad/Igualdad. Y una dimensión de naturaleza resolutiva o de resultados: (8) la Responsividad.

Las preguntas orientadoras del texto son las siguientes: ¿cómo es la calidad de la democracia - incluso sus fortalezas, debilidades y perspectivas - de Brasil y Perú?, ¿qué semejanzas, diferencias e implicaciones tienen las experiencias de experiencias democráticas de ambos países?, ¿cuáles actores político-sociales son prioritarios y forman parte de una agenda ampliada de estudio e investigación sobre la temática en ambos países?

En esta perspectiva, lo que más interesa para los fines del presente trabajo es el análisis comparativo de la democracia brasileña y peruana en el contexto actual. Esta opción metodológica permite apreciar luces y sombras, avances y desafíos, conquistas y rezagos en ambos países. Se trata de una agenda de investigación ampliada, en la que no faltan cuestiones de cultura política, tecnología electoral, predominio de la ley, organizaciones políticas, hábitos electorales, gobernabilidad, representación, legitimidad, ciudadanía, derechos humanos y agenda de reformas políticas.

\section{Estado de Derecho}

El Estado de Derecho es la aplicación de la justicia y el cumplimiento de las normas legales por las diversas instituciones del Estado. Esa dimensión también se refiere a la aplicación coherente de la justicia en casos equivalentes, independientemente de diferencias de clase, condición social, cultural o de poder de los participantes en esos procesos sobre la base de procedimientos preestablecidos y conocidos por todos (O’DONNELL, 1997; MORLINO, 1998). Esto se desdobla en el estudio de la percepción de la corrupción, en el orden civil, en la seguridad ciudadana, en el acceso a la justicia, entre otros factores.

Aunque no existen datos completamente objetivos para mensurar la corrupción en cada país, el indicador desarrollado por Transparencia Internacional con base en percepciones ciudadanas demuestra que Brasil, en 2016, alcanzó una calificación de 40 puntos según el reporte de 2016, ubicándose en el puesto 79% ya Perú, con 35 puntos, fue clasificado en el puesto $101^{\circ}$, de 176 países evaluados (TRANSPARENCY 
Artigo original

Hegemonia - Revista Eletrônica do Programa de Mestrado em Direitos Humanos, Cidadania e Violência/Ciência Política do Centro Universitário Unieuro

ISSN: $1809-1261$

UNIEURO, Brasília, número 23, Janeiro a Junho de 2018, pp. 27-54.

INTERNATIONAL, 2017). Evidentemente, la corrupción afecta cualquier régimen político, en mayor medida a las democracias, pues el déficit de legitimidad de sus instituciones conlleva no sólo la falta de apoyo a este tipo de régimen sino el encarecimiento de las transacciones, el énfasis de las asimetrías entre ciudadanos y con ellos el deterioro de la vida cotidiana.

Latinobarómetro (2016) constata que en los dos países hay un alto y creciente rechazo en cuanto a tolerar la corrupción. En Brasil, sólo el 34\% de los encuestados aceptaría algún grado de corrupción, siempre que se pudiesen solucionar los problemas del país. Entretanto, en Perú ese mismo indicador de tolerancia social a la corrupción alcanza el 28\% de los encuestados, por debajo de la media latinoamericana que es de 39\%.

Ello ha repercutido en las evaluaciones sobre el desempeño del poder judicial. En efecto, en términos agregados la confianza en las instituciones de los poderes judiciales latinoamericanos se ha incrementado entre 2015 a 2016, pasando de 26\% a 30\%. Específicamente en Brasil la popularidad de los jueces de forma individual es expresiva. La encuesta de Ipsos Brasil (2017) muestra que la aprobación del sistema judicial por la opinión pública puede llegar a ser inclusive superior que la propia aprobación del actual presidente de la República Michel Temer. Ya en Perú, al contrario, la desaprobación del Poder Judicial llega a 71\% (GFK, 2017). El descredito del poder judicial peruano es de larga data. Acontece que, para una importante parcela de la opinión pública peruana, el poder judicial ha llegado a ser visto como uno de los actores políticos y económicos de importancia en el país que goza de menor independencia relativa (FELD Y VOIGT, 2003). En consecuencia, parece evidente que no han sido plenamente exitosos los esfuerzos de diferentes gobiernos peruanos para reformar y modernizar el sistema de justicia. Paralelamente, es importante tener presente que "hay muchas características deseables en el ideal de un Estado de Derecho, pero en sí mismo un Estado de Derecho, en el cual rigen efectivamente las leyes establecidas, no es necesariamente democrático" (LEVINE Y MOLINA, 2007, p. 41).

El problema de la inseguridad ciudadana está presente en ambos países y ello incide directa e indirectamente en el apoyo de los ciudadanos al sistema político (CARRIÓN ET $A L, 2012$, p. 97). En Perú, el 61\% de los ciudadanos considera a la inseguridad ciudadana 
Artigo original

Hegemonia - Revista Eletrônica do Programa de Mestrado em Direitos Humanos, Cidadania e Violência/Ciência Política do Centro Universitário Unieuro

ISSN: $1809-1261$

UNIEURO, Brasília, número 23, Janeiro a Junho de 2018, pp. 27-54.

como el más importante de los problemas que afecta al país (GFK, 2017). Ya en Brasil no lo es. Ello se debe, en buena medida, al estatus social de las víctimas, a la distribución de la percepción de la violencia en un país de tamaño continental, y a la baja eficacia y heterogeneidad de políticas públicas de seguridad - siendo que, constitucionalmente, las políticas de seguridad pública son de responsabilidad de los gobiernos provinciales o estaduales.

A diferencia de Brasil, en Perú la tasa de homicidios es relativamente baja y estable. ${ }^{3}$ Sin embargo, el alto nivel de victimización persistente en el Perú y en Brasil puede estar asociada a la ausencia de políticas públicas concretas orientadas a la juventud en los dos países. La percepción de inseguridad contribuye a socavar el Estado de Derecho pues torna visible a un Estado omiso en el cumplimiento de sus responsabilidades y en las ineficaces políticas de seguridad pública en los dos países.

Se infiere de lo expuesto que la subdimensión seguridad individual y el orden civil que componen el análisis del Estado de Derecho - continúa siendo un problema significativo para la democracia brasileña y peruana. Como mencionado, los indicadores de la distribución de la violencia son alarmantes.

Tanto en Brasil como en Perú el componente estructural de la violencia afecta directamente a los sectores más vulnerables de la sociedad, como resultado de la situación de pobreza y desigualdad. Los pobres, además de su posición asimétrica en cuanto al acceso a recursos públicos, sufren también obstáculos indirectos en el marco de la estructura socioeconómica. Paralelamente, no se pueden ignorar los criterios subjetivos o raciales, que cuestionan los principios de igualdad de oportunidades o de disminución de la "desventaja" social para superar la reproducción permanente de las precarias condiciones materiales de vida. En Brasil esta segregación estructural ha afectado históricamente a los afrodescendientes, desde épocas que remiten a su migración forzada como esclavos. En Perú una situación análoga se evidencia de forma velada tanto para afrodescendientes como para grupos indígenas. Desde entonces en pocas oportunidades

\footnotetext{
${ }^{3}$ El índice de homicidios en Perú es bajo, cuando comparado con otros países latinoamericanos. En 2014, se estableció la cifra de 6,7 homicidios por cada 100 mil habitantes. Mientras que en Brasil la cifra llegó a 24,6 homicidios por cada 100 mil habitantes. Vale agregar que, en términos absolutos, ello significa que, en 2014, se registraron 2,076 y 50,674 homicidios, respectivamente.
} 
Artigo original

Hegemonia - Revista Eletrônica do Programa de Mestrado em Direitos Humanos, Cidadania e Violência/Ciência Política do Centro Universitário Unieuro

ISSN: $1809-1261$

UNIEURO, Brasília, número 23, Janeiro a Junho de 2018, pp. 27-54.

se implementaron políticas públicas de inclusión e integración social, consolidando una serie de deficiencias en materia de salud, educación, habitación, e ingresos de estos mayoritarios segmentos.

En esa línea, parece plausible verificar que la situación de violencia es reflejo de una sociedad en la cual las nociones de democracia y de Estado de Derecho han tendido a ser relativizadas por las elites brasileñas y peruanas. La configuración del mapa de la violencia estructural en Brasil y en Perú demuestra como la violencia se instala en las regiones más pobres y zonas más carentes del país. Configurando de ese modo la persistencia de sociedades no pacificadas. Al contrario, se trataría de sociedades permeadas por una diversidad de conflictos latentes. En consecuencia, parece evidente que la acción del gobierno no ha conseguido una efectiva inclusión ciudadana y donde el Estado de Derecho se presenta de forma endeble.

\section{Rendición de Cuentas Electoral e Interinstitucional}

La rendición de cuentas - o Accountability, en inglés - ha sido estudiada exhaustivamente por importantes autores vinculados a la ciencia política, y a las ciencias sociales, en general. Entre este grupo de autores reconocidos destacan Guillermo O’Donnell (1997), Andreas Schedler (2008, 1999), Philippe Schmitter (2004), y Leonardo Morlino (2016; 2011).

Morlino (2016, p. 29) sugiere que el concepto de rendición de cuentas implica necesariamente "la obligación de los líderes políticos electos de responder por sus decisiones políticas cuando les es pedido por los ciudadanos-electores u otros cuerpos constitucionales." Schmitter (2004, p. 47) entiende que la rendición de cuentas "implica un intercambio de responsabilidades y potenciales sanciones entre autoridades y ciudadanos, todo ello complicado adicionalmente por el hecho de que un variado y competitivo conjunto de representantes típicamente se interpone entre ambos." Schedler (2008) enfáticamente constata lo siguiente:

En esencia, en el ámbito político, afirmamos que la noción de rendición de cuentas tiene dos dimensiones básicas. Incluye, por un lado, la obligación de políticos y funcionarios de informar sobre sus decisiones y de justificarlas (answerability). Por 
Artigo original

Hegemonia - Revista Eletrônica do Programa de Mestrado em Direitos Humanos, Cidadania e Violência/Ciência Política do Centro Universitário Unieuro

ISSN: $1809-1261$

UNIEURO, Brasília, número 23, Janeiro a Junho de 2018, pp. 27-54.

otro, incluye la capacidad de sancionar a políticos y funcionarios en caso de que hayan violado sus deberes públicos (enforcement).

Estos reconocidos teóricos consideran que la rendición de cuentas es una condición necesaria de las democracias contemporáneas. Sin pretender realizar en este espacio una completa exégesis del concepto en referencia, es evidente que la rendición de cuentas reivindica la necesidad de monitorear, fiscalizar, y eventualmente castigar o premiar gobernantes, autoridades intermedias, y funcionarios públicos, por las acciones realizadas en el ejercicio de sus funciones públicas y de acuerdo con las leyes vigentes.

Según O’Donnell (1997), la rendición de cuentas puede ser vertical u horizontal. La primera implica la relación directa entre gobernantes y gobernados en el momento de la realización de procesos electorales abiertos, competitivos, y transparentes. En tales circunstancias, los ciudadanos-electores evalúan la posibilidad de premiar o substituir quiere decir, reelegir o cambiar - a las autoridades ejecutivas y legislativas de una comunidad. La segunda fue definida por el politólogo argentino en los siguientes términos:

llamo rendición de cuentas horizontal: es la existencia de organismos estatales que están legalmente habilitados y autorizados, y de hecho dispuestos y capacitados, para emprender acciones que abarcan desde la fiscalización rutinaria hasta sanciones penales o destitución, en relación con actos u omisiones de otras instituciones del Estado, que puedan calificarse, en principio o presuntamente, como ilícitos [O’DONNELL, 1997, p. 13].

Paralelamente, Leonardo Morlino (2016) constata la existencia de ambos tipos ideales de rendición de cuentas mencionados por O’Donnell. Pero les atribuye una nueva nomenclatura: la rendición de cuentas electoral, a la primera, y la rendición de cuentas interinstitucional, a la segunda. Al respecto, parece pertinente agregar que una definición mínima de rendición de cuentas implica, en el marco de la republicana división y equilibrio entre los poderes del Estado, la responsabilidad de las autoridades para responder a otras autoridades del Estado y también a ciertos actores no-estatales con reconocido prestigio y conocimiento para valorizar los actos administrativos; bien como la mutua fiscalización 
Artigo original

Hegemonia - Revista Eletrônica do Programa de Mestrado em Direitos Humanos, Cidadania e Violência/Ciência Política do Centro Universitário Unieuro

ISSN: $1809-1261$

UNIEURO, Brasília, número 23, Janeiro a Junho de 2018, pp. 27-54.

entre los entes contralores estatales - y de la sociedad civil organizada - para evitar los excesos, los abusos, la corrupción y otros crímenes claramente tipificados.

Específicamente en lo concerniente a la Rendición de Cuentas Electoral de Brasil y Perú, parece pertinente ponderar que los problemas de esta dimensión no se refieren a la confiabilidad de los procesos electorales y sus resultados. Informes de observadores de organismos internacionales como Naciones Unidas, la Organización de Estados Americanos y de la Unión Europea corroboran tanto la confiabilidad y la transparencia de los procesos electorales brasileños y peruanos. En general, aquellas instituciones destacan la posibilidad de contestación judicial de los resultados, la neutralidad de las fuerzas armadas y fuerzas de seguridad durante la votación, y la libertad para el trabajo de monitoreo internacional de las elecciones. Igualmente, la mayoría de las veces los resultados de los comicios no son cuestionados por las fuerzas políticas y sociales.

En lo correspondiente a la organización y al derecho electoral, el mayor problema que se manifiesta en las elecciones peruanas o brasileñas es la ausencia de transparencia en el financiamiento de las campañas electorales. Podemos afirmar que en Perú el problema es mucho mayor que en Brasil. Pero se evidencia que en los dos países existen graves problemas de financiamiento ilegal y crímenes conexos. Así, muchos de los escándalos de corrupción que han surgido en los últimos años tienen relación en parte o totalmente con la contabilidad interna de los partidos y al no declarar fondos para los candidatos - esto es, el así llamado "caja dos” de campaña. Igualmente, se percibe la necesidad de los partidos en obtener recursos para pagar deudas acumuladas de elecciones anteriores. Aunque existen normas rígidas los órganos de control y fiscalización, los resultados alcanzados por las instancias competentes han sido insuficientes en ambos países.

En cuanto a la libertad de organización partidista, se evidencia que no existen grandes o espurios impedimentos a la organización de partidos en ambos países. Lo que la legislación no admite es la formación de partidos que no respeten determinados principios, entre ellos: la soberanía nacional, el régimen democrático, el pluripartidismo y los derechos fundamentales de las personas. No obstante, es cada vez más evidente una creciente dificultad en la capacidad de movilización de la militancia partidaria. En general, ello se debe a una creciente desafección de los partidos por la población.

En lo referente a la presencia y estabilidad de las alternativas políticas, parece pertinente constatar que actualmente existen 35 partidos oficialmente registrados en Brasil, 
Artigo original

Hegemonia - Revista Eletrônica do Programa de Mestrado em Direitos Humanos, Cidadania e Violência/Ciência Política do Centro Universitário Unieuro

ISSN: $1809-1261$

UNIEURO, Brasília, número 23, Janeiro a Junho de 2018, pp. 27-54.

siendo que 26 de ellos tienen representación parlamentaria. Como es discutido en la sección sobre Competición Política, esa fragmentación partidaria genera importantes implicaciones al régimen democrático. En el caso de Perú el número de partidos es comparativamente menor y el problema prioritario concerniente a los mismos es la falta de continuidad en el tiempo de las alternativas políticas. La libertad para organizar partidos en el Perú es alta, y por ello hay presencia de casi 14 organizaciones políticas (MAINWARING Y SCULLY, 1995; MAINWARING, BEJARANO Y PIZARRO, 2008).

En lo concerniente a la Rendición de Cuentas Interinstitucional conviene constatar que la formación de amplias coaliciones posibilitó a Brasil y Perú la obtención de cierta gobernabilidad. Las únicas excepciones parciales de esa regularidad fueron la breve y turbulenta administración de Fernando Collor de Mello (1990-1992), las vicisitudes del gobierno de Alberto Fujimori - autogolpe en 1992, y renuncia anticipada en 2000 -, y más recientemente el traumático proceso de irregular interrupción del mandato de Dilma Rousseff. De modo general, es posible constatar que los poderes Ejecutivo y Legislativo de ambos países generalmente han conseguido actuar de forma coordinada, ya que la disciplina partidista en las votaciones es lo que prevalece en la base de apoyo al gobierno en el parlamento (LIMONGI Y FIGUEIREDO, 1995).

En cuanto a la información plural e independiente, podemos afirmar que, tanto en Brasil como en Perú, no hay problemas de libertad de expresión. Por lo general, la prensa realiza un trabajo independiente de investigación periodística que, con frecuencia, revela casos de corrupción. Vale tomar nota de que la propiedad de los medios de comunicación es concentrada, dado que los grandes grupos comunicacionales pertenecen a pocas familias y en los últimos años han sido cuestionados por intentar imponer una agenda de reformas, en alianza con partidos políticos, y por encima de las instituciones democráticas. ${ }^{4}$

\footnotetext{
${ }^{4}$ Paralelamente, la explotación de emisoras de radio y televisión, que son concesiones públicas, es utilizada, en general, como moneda para obtención de apoyo político, lo que hace con que muchas estén en manos de políticos e incluso de grupos religiosos. Algo semejante se puede afirmar con relación a la violencia contra los profesionales de la prensa - particularmente en el caso brasileño.
} 
Artigo original

Hegemonia - Revista Eletrônica do Programa de Mestrado em Direitos Humanos, Cidadania e Violência/Ciência Política do Centro Universitário Unieuro

ISSN: $1809-1261$

UNIEURO, Brasília, número 23, Janeiro a Junho de 2018, pp. 27-54.

\section{Participación Política}

Los principales modelos teóricos y metodológicos disponibles para el estudio de la calidad de la democracia colocan a la Participación Política como una de sus dimensiones más destacadas. En el modelo analítico propuesto por Morlino, y que es de particular importancia para los fines del presente artículo, la Participación Política - o simplemente PP - es una de las ocho dimensiones fundamentales. Concretamente, la Participación Política es definida en los siguientes términos:

El conjunto total de comportamientos - convencionales o no convencionales, legales o en el límite de la ley - que permiten a los hombres y a las mujeres, en forma colectiva o individual, crear, revivir o fortalecer la identificación grupal, o tratar de influir en el reclutamiento o en las decisiones de las autoridades políticas (representativas o gubernamentales) para mantener o cambiar la asignación de los valores existentes [MORLINO, 2016, p. 32].

Así las cosas, en el marco de los estudios de la calidad de la democracia, la Participación Política pretende auscultar los mecanismos que permiten a los ciudadanos influenciar en las políticas de las autoridades con destaque en los siguientes tópicos: (i) las principales condiciones que afectan e inciden en la participación, (ii) los canales institucionales disponibles para ejercer la participación política tanto electoral, como cívica, deliberativa y hasta radical, y (iii) las reacciones ciudadanas en el esfuerzo de ampliar, enraizar y calificar las alternativas disponibles para influir en el gobierno y en la sociedad.

De momento, parece evidente que la Participación Política se erige en un fenómeno complejo, multifacético, y altamente significativo. En ese contexto, aquí se analizan concretamente los límites y las vicisitudes de la Participación Política en Brasil y Perú.

En Brasil, la Constitución Federal de 1988 ha garantizado a los brasileños una amplia y generosa ciudadanía electoral, bien como numerosas oportunidades para el ejercicio de la participación política convencional. Desde las elecciones presidenciales de 1989, el voto en Brasil es universal a partir de los 16 años, obligatorio, directo y secreto. Para conseguirlo, basta a los ciudadanos del Brasil inscribirse en el registro electoral 
Artigo original

Hegemonia - Revista Eletrônica do Programa de Mestrado em Direitos Humanos, Cidadania e Violência/Ciência Política do Centro Universitário Unieuro

ISSN: $1809-1261$

UNIEURO, Brasília, número 23, Janeiro a Junho de 2018, pp. 27-54.

correspondiente, procedimiento que usualmente es expedito y simple (D’ARAÚJO, 2009).

En Perú, de forma semejante, la Constitución de 1993 establece el sufragio universal. El ejercicio del voto es una obligación legal, cuyo incumplimiento supone pagar multas altas. El derecho al voto se adquiere a partir de los 18 años. En Brasil hay una cierta flexibilidad para quien no vote por no encontrarse en su lugar domicilio electoral, pudiendo presentar una justificativa hasta 60 días después de las elecciones. En general, el abstencionismo en ambos países se ubica en $20 \%$ del electorado.

Es importante agregar que la ciudadanía no está desinteresada de la política, en general, y de la calidad de la democracia, en particular. Investigaciones de opinión pública auspiciadas por el Senado brasileño, de marzo de 2016, sugieren que 74\% de los entrevistados apoyan la democracia y concuerdan con la frase: "La democracia es siempre la mejor forma de gobierno" (DATASENADO, 2016b, p. 29).

Ya el apoyo de la democracia de parte de los peruanos cayó de 56\% en 2015 a 53\% en 2016, según la prestigiosa encuesta regional de Latinobarómetro (2016). En el índice que mide el respaldo al régimen democrático, la región también registró una baja provocada por la crisis económica, la corrupción y la insatisfacción con los servicios públicos.

Vale agregar que los ciudadanos brasileños siguen con mucha frecuencia y cotidianamente las noticias sobre la política. De hecho, el 47\% de los entrevistados declaró que busca y sigue las noticias sobre la política más de cinco días por semana. Ya en Perú se observa que el $42 \%$ de los peruanos acompaña siempre las noticias políticas, teniendo como fuente principal la televisión.

Los teóricos de la Participación Política reconocen la relevancia no solamente de la ciudadanía electoral, como también lo concerniente a la ciudadanía cívica y al capital social. En ese sentido, la Participación también puede auscultarse por la vía de las actividades realizadas por los ciudadanos en ciertas organizaciones políticas y sociales. Con relación a la Participación en el marco de organizaciones políticas - también llamada de partidismo - es necesario verificar los temas de: (i) la identificación/preferencia partidaria, (ii) las condiciones y posibilidades de afiliación y de militancia, y (iii) la democracia al interior de los partidos políticos.

En cuanto a la ciudadanía cívica, los teóricos participativos recomiendan aproximarse, entender e interpretar las capacidades de los habitantes de un espacio público 
Artigo original

Hegemonia - Revista Eletrônica do Programa de Mestrado em Direitos Humanos, Cidadania e Violência/Ciência Política do Centro Universitário Unieuro

ISSN: $1809-1261$

UNIEURO, Brasília, número 23, Janeiro a Junho de 2018, pp. 27-54.

específico para contribuir activamente en organizaciones político-sociales, sea de forma obligatoria o voluntaria. Estas organizaciones pueden ser sindicatos, asociaciones profesionales, grupos vecinales, organizaciones no gubernamentales, movimientos sociales emergentes, entre otros. Al respecto, conviene recordar que Robert Putnam (2005) ha reconocido, desde la década de 1970, la alta relevancia de este tipo de actividades, a las que denomina genéricamente como capital social. Se entiende que aquellas comunidades con mayor capital social tienden a desarrollar una participación mejor calificada y, consecuentemente, una democracia de mayor calidad.

En Brasil existe una trayectoria de estímulo y reconocimiento a la participación de los ciudadanos en organizaciones políticas (partidos) y sociales (asociaciones, sindicatos). Esta participación político-social está respaldada por la Constitución y por numerosas leyes secundarias. Paradojalmente, algunos analistas consideran que la legislación que regula la temática ha sido excesivamente flexible, permisible y laxa, lo que ha resultado en una evidente proliferación de organizaciones políticas y sociales.

En el caso peruano si bien la participación electoral es alta, la participación en las organizaciones políticas es muy baja. Como se ha mencionado en Perú existen casi dos decenas de partidos políticos. Sin embargo, cuando nos referimos a la participación ciudadana en otro tipo de entidades, como las sindicales, esta se encuentra reducida debido a la flexibilización de las relaciones de trabajo. Esas reformas laborales han afectado la relación de los trabajadores formales con los sindicatos. Otro tanto se debe al expresivo número de trabajadores informales en la economía peruana que llega a casi $80 \%$ del total del mercado laboral. Ya la participación de los peruanos por medio de organizaciones religiosas, asociaciones de padres y madres de familia y de juntas vecinales es más significativa. El 27,9\% de los peruanos entrevistados en 2012 indicaron que habían asistido a una reunión de la comunidad por lo menos una vez durante el año anterior (CARRIÓN ET AL, 2012, p. 39). Esto ubicó al Perú justo por encima del promedio de América Latina, que era del $26,6 \%$.

En cuanto a la participación ciudadana en el marco de movimientos sociales, parece apropiado destacar que algunos de estos actores y movimientos político-sociales han llegado a tener una influencia e incidencia relevante en la política nacional y en la calidad de la democracia de ambos países. Tal es el caso del gremio de los abogados, de las confederaciones de sindicatos de trabajadores, de las asociaciones de empresarios, de los 
Artigo original

Hegemonia - Revista Eletrônica do Programa de Mestrado em Direitos Humanos, Cidadania e Violência/Ciência Política do Centro Universitário Unieuro

ISSN: $1809-1261$

UNIEURO, Brasília, número 23, Janeiro a Junho de 2018, pp. 27-54.

movimientos sociales rurales, y de ciertas organizaciones no gubernamentales. Se trata, por tanto, de una participación cívica muy activa, dinámica, efervescente y, en general, constructiva, leal y convergente con los esfuerzos orientados a la elevación y al perfeccionamiento de la calidad de la democracia en cada país.

La participación no convencional usualmente emergió espontáneamente y desde abajo - quiere decir, desde los sectores subalternos de la sociedad generando movimientos sociales de gran importancia. Sin embargo, en algunos periodos de la historia brasileña estos se han encontrado cooptada por el Estado, la misma que podemos decir ha evidenciado algunos beneficios como el de mejorar la formulación y ejecución de políticas públicas sea esta en el reconocimiento de los derechos de minorías que luchan contra el racismo, la homofobia o como en el caso de los movimientos ambientalistas. En contraste, en Perú los movimientos sociales no han conseguido afectar decididamente una serie de pautas pendientes en cuanto al reconocimiento de derechos o en el combate a diversas formas de violencia.

En esta línea, el caso brasileño es particularmente ilustrativo para los fines del presente estudio comparativo. En efecto, parece pertinente constatar que desde el retorno al orden constitucional y a la democracia, en 1985, Brasil tuvo relativamente pocas experiencias de participación no convencional. Posiblemente las manifestaciones populares en la época del proceso de impedimento presidencial de Fernando Collor, en 1992, fuese uno de esos casos. Algunos investigadores sugieren que esa limitada predisposición a participar en demostraciones populares masivas se podría entender en el marco de las acentuadas carencias en que se han debatido las clases populares del país, bien como a la violencia policial con relación a los movimientos contestatarios, al gigantismo del país, y a las discriminaciones existentes entre los diferentes segmentos de la sociedad local (AVRITZER, 2016).

Sea como fuere, a partir de 2013, y muy particularmente durante el año de 2016, el Brasil ha sido envuelto por una inesperada, masiva y dramática ola de manifestaciones y otras demostraciones de participación no convencional. Las mismas culminaron el día 13 de marzo de 2016, con la mayor manifestación popular en la historia política del país, por cuanto más de seis millones de ciudadanos se volcaron a las calles de muchas capitales provinciales, municipales y en la propia capital federal para protestar, para exigir cambios y demostrar su capacidad de articulación. 
Artigo original

Hegemonia - Revista Eletrônica do Programa de Mestrado em Direitos Humanos, Cidadania e Violência/Ciência Política do Centro Universitário Unieuro

ISSN: $1809-1261$

UNIEURO, Brasília, número 23, Janeiro a Junho de 2018, pp. 27-54.

Según una investigación de opinión pública realizada en los días subsiguientes a la jornada de 13 de marzo, más de 97\% de los entrevistados en todo el país tuvieron noticias e informaciones de la manifestación (DATASENADO, 2016b). Asimismo, 19\% de los entrevistados afirmaron que ellos mismos habían participado en la referida manifestación, ya que la misma fue realizada simultáneamente en casi todas las capitales provinciales y en muchas sedes municipales del país. La misma fuente sugiere que el perfil de los manifestantes ha sido multifacético. Destacase un ligero predominio masculino (56\%), la gran afluencia de jóvenes y adultos-jóvenes (48\% con edades entre 16 y 39 años), personas de media y alta escolaridad ( $93 \%$ con educación media y superior completa), e ingresos medios y altos; configurando una cierta hegemonía de las clases medias y altas de la sociedad. Según esa investigación de opinión pública, las principales motivaciones de la manifestación de 13 de marzo de 2016 incluían fundamentalmente dos asuntos: Protestar contra la corrupción (59\%) y Apoyar el proceso de impedimento presidencial de Dilma Rousseff (34\%); en tercer lugar se afirmó la necesidad de Protestar contra la situación económica del Brasil (6\%).

La llamada teoría de la democracia deliberativa ha sido uno de los últimos desdoblamientos de la teoría política contemporánea. Generalmente asociada a las contribuciones de Habermas, de Rawls y, en menor medida, de Hannah Arendt, los así llamados demócratas-deliberacionistas reivindican una ampliación del debate público sobre las principales políticas y sobre otras decisiones de cumplimiento obligatorio por parte de los ciudadanos. En esa perspectiva, la teoría deliberativa podría acabar enriqueciendo tanto la participación política de los ciudadanos, como la calidad de la democracia realmente existente.

La propia noción de deliberación exige que las autoridades discutan, justifiquen y legitimen delante de la población sus decisiones. En esta línea, es evidente que la deliberación presupone tener la capacidad de actuar y de escuchar en reciprocidad. También se da por hecho que los actores político-sociales están dispuestos a construir consensos mínimos, en beneficio de sociedades que son, por naturaleza, plurales, dinámicas, desiguales, efervescentes y, en algunos casos, conflictivas y desiguales.

Aunque frecuentemente cuestionada por ser un tanto utópica, ingenua o excesivamente idealista, algunas experiencias de democracia deliberativa y de participación política han acabado siendo ejemplarmente aleccionadoras - y hasta paradigmáticas. En el 
Artigo original

Hegemonia - Revista Eletrônica do Programa de Mestrado em Direitos Humanos, Cidadania e Violência/Ciência Política do Centro Universitário Unieuro

ISSN: $1809-1261$

UNIEURO, Brasília, número 23, Janeiro a Junho de 2018, pp. 27-54.

caso brasileño, usualmente se menciona como ejemplo más acabado y virtuoso la experiencia de los llamados Presupuestos Participativos - u Orçamentos Participativos. Implantados desde 1989 en Porto Alegre y otras ciudades, los Presupuestos Participativos son mecanismos gubernamentales que les permiten a los ciudadanos influenciar y decidir la asignación/distribución de ciertos recursos públicos según las prioridades y necesidades vecinales y/o locales. Conviene insistir en que las experiencias más exitosas de Presupuestos Participativos han sido documentadas en comunidades vecinales y locales que cuentan con sólidos vínculos de cooperación, de confianza interpersonal, de solidaridad y de capital social.

En síntesis, es evidente que, a pesar de las referidas críticas y de ciertas limitaciones prácticas de la teoría deliberativa, existen algunas iniciativas inspiradas - directa o indirectamente - en la deliberación que han resultado harto exitosas, ejemplares y convalidadas en el Brasil - siendo que algunas de ellas, como es el caso de los Presupuestos Participativos, han sido replicadas en Perú y en otros países del continente latinoamericano. Mucho de ese suceso ha dependido, evidentemente, de la participación cívica, del capital social, del empoderamiento, de la confianza interpersonal, del diálogo constructivo y de los vínculos de solidaridad desplegados por los ciudadanos y sus autoridades locales/vecinales. Por tanto, no cabe duda de que este tipo de mecanismos e iniciativas que estimulan la participación acaban alimentando y expandiendo el espacio público, la sociedad civil y la calidad de la democracia.

\section{Competencia Política}

La competencia político-ideológica es uno de los elementos fundamentales en el estudio de los sistemas de partidos y de la calidad de la democracia. Resumidamente, esta dimensión explora el cotidiano de las actividades de la clase política, bien como las contradicciones entre partidos políticos y la correlación de fuerzas entre actores gubernamentales y opositores - además de las divergencias entre mayorías y minorías parlamentarias. Efectivamente, la competición puede acontecer al interior de cada partido político, al interior de las coligaciones políticas, en el contexto general del sistema político, y eventualmente entre actores políticos y actores sociales (poderes facticos, movimientos sociales, potencias extranjeras). Obviamente, las democracias de más alta calidad aceptan 
Artigo original

Hegemonia - Revista Eletrônica do Programa de Mestrado em Direitos Humanos, Cidadania e Violência/Ciência Política do Centro Universitário Unieuro

ISSN: $1809-1261$

UNIEURO, Brasília, número 23, Janeiro a Junho de 2018, pp. 27-54.

la alternancia en el poder, el pluralismo político, e incluso la competencia democrática al interior de los partidos.

Desde la proclamación de la República, en 1889, Brasil tiene una larga tradición de competencia política - aunque muchas veces las elecciones y la representación política adolecieran de graves limitaciones democráticas. Actualmente, el sistema de partidos vigente en el país es bastante exuberante. De inicio, destaca el gran número - 35 en total - de partidos políticos registrados en el Tribunal Supremo Electoral.

Evidentemente, se trata de un sistema de partidos muy fragmentado. La necesidad de apoyo incentiva conductas poco éticas entre actores políticos. Esa fragmentación excesiva también obliga a los Ejecutivos y a los legisladores a establecer alianzas o coligaciones políticas que permitan un mínimo de gobernabilidad. Asimismo, en ambos países el pluralismo político puede ser considerado bastante amplio, ya que incluye a organizaciones políticas de diferentes posiciones del espectro ideológico derecha-centroizquierda. Conviene agregar que los requisitos para crear nuevos partidos políticos brasileños y peruanos han sido relativamente flexibles - entretanto, está excluida la posibilidad de crear partidos extremistas, étnico-religiosos, o regionalistas. Todavía, los partidos políticos brasileños y peruanos reciben asistencia financiera gubernamental, reconocimiento jurídico, y autonomía para la organización interna.

En Perú no hay partidos fuertes que dominen la política o que restrinjan la opción electoral efectiva - no hay partidocracia-, y con frecuencia surgen nuevos partidos y organizaciones políticas. El sistema también es bastante abierto, con un número alto de partidos que compiten en elecciones nacionales. También es posible verificar una distribución de votos muy amplia entre los partidos. En 2001, 2006 y 2011, compitieron en cada elección un promedio de 17 partidos en la disputa para el congreso unicameral, y 13 partidos en las elecciones presidenciales de 2016.

En ambos países surgen, así, las correspondientes bases de sustentación del Ejecutivo, con objetivo de aprobar las iniciativas legislativas de los titulares del ejecutivo, reducir las embestidas de la oposición, y garantizar la manutención de los propios mandatos. En síntesis, tanto en Brasil como en Perú las bases de sustentación en el legislativo trabajan para garantizar la gobernabilidad - y la viabilidad electoral - de los titulares del Ejecutivo. En compensación, los miembros de esas bases de sustentación 
Artigo original

Hegemonia - Revista Eletrônica do Programa de Mestrado em Direitos Humanos, Cidadania e Violência/Ciência Política do Centro Universitário Unieuro

ISSN: $1809-1261$

UNIEURO, Brasília, número 23, Janeiro a Junho de 2018, pp. 27-54.

legislativa normalmente exigen del Ejecutivo cargos, recursos, y hasta cierta tolerancia con los desvíos de conducta y otras prácticas ilegítimas, abusivas o simplemente corruptas.

Es evidente que este tipo de relaciones entre Ejecutivo-Legislativo depende también de la habilidad - y de los recursos financieros - que el gobernante pueda movilizar en favor de sus aliados en las cámaras legislativas correspondientes. Ello se debe a que, en los últimos tiempos, ha predominado en Brasil y en Perú la formación de coligaciones no tradicionales, pragmáticas, semi-consistentes e ideológicamente amplias - incluyendo partidos de diferentes orientaciones programáticas -; lo que genera una mayor complejidad en el proceso de tomada de decisiones.

En este contexto, ha sido la ruptura de la segunda coligación encabezada por Dilma Rousseff (Partido dos Trabalhadores-PT) durante el período 2015-2016, el acontecimiento que resultó en la aprobación del impedimento presidencial y en la asunción - nada desinteresada ni republicana - del vicepresidente Michel Temer (Partido do Movimento Democrático Brasileiro-PMDB). Desde la perspectiva de la competencia política, este episodio ha provocado una dramática recomposición del sistema político, ya que antiguos aliados del PT devenidos en adversarios - PMDB y otros, muchos de ellos con sus líderes acusados por graves delitos de corrupción política - no dudaron en aproximarse del Partido da Social Democracia Brasileira-PSDB - organización derrotada en los cuatro últimos procesos electorales para presidente de la República - y asumieron el poder, en medio a una considerable repulsa de la ciudadanía.

El PMDB y el PSDB, junto a otras organizaciones políticas minoritarias de centroderecha, consiguieron alcanzar el poder político federal, sin someterse al veredicto de las urnas. Y, más aún, han implementado un programa de gobierno que difícilmente habría sido aprobado por la población en comicios regulares. Ese programa de gobierno implementado por la coligación PMDB-PSDB provoca las siguientes tendencias: (i) la suspensión del principio de la soberanía popular, (ii) la disminución de conquistas sociales, (iii) el irrespeto a los votos del pueblo brasileño, (iv) la abrupta recomposición del sistema de partidos, y (v) un cuestionamiento de la legitimidad del gobierno Temer.

En consecuencia, parece evidente que el impedimento presidencial de Rousseff afecta negativamente la dimensión de Competencia Política, bien como de otras dimensiones de la calidad de la democracia, especialmente el Estado de Derecho, la Prestación de Cuentas, y la Responsividad. 
Artigo original

Hegemonia - Revista Eletrônica do Programa de Mestrado em Direitos Humanos, Cidadania e Violência/Ciência Política do Centro Universitário Unieuro

ISSN: $1809-1261$

UNIEURO, Brasília, número 23, Janeiro a Junho de 2018, pp. 27-54.

Paralelamente, en Perú se evidencia una erosión lenta en las relaciones entre estos dos poderes. Tal proceso tiene su origen en las recientes disputas electorales que fueron extremadamente polarizadas. Si bien es cierto que el fujimorismo y el partido de Pedro Pablo Kuczynski representan la continuidad del modelo económico, lo cierto es que la persistencia fricción acaba erosionando al Ejecutivo, siendo que el mismo tiene poca capacidad de maniobrar políticamente. Así las cosas, Kuczynski se ha refugiado en el Ejecutivo, con un conjunto de tecnócratas que vienen administrando el país desacoplados de las demandas urgentes de la sociedad peruana, situación que puede llevar a un colapso de la gestión actual con impredecibles consecuencias.

\section{Libertades e Igualdad}

En lo referente a las Libertades, Brasil y Perú se encuentran relativamente por encima de la media entre los países de la región. En términos formales, las constituciones de ambos países garantizan a sus ciudadanos un conjunto de derechos vinculados a las libertades, a la promoción de los derechos humanos, a la búsqueda del consenso entre diversos actores políticos y sociales, a la explícita condena de la tortura, de la esclavitud, de la discriminación, entre otros.

Si por una parte existen garantías formales, en Brasil y en Perú los datos de la realidad sobre la dimensión Dignidad Personal expresan algunos elementos contradictorios. Si bien la pena capital no existe legalmente, entretanto, los agentes del Estado generalmente no son responsabilizados por los altos índices de muertes generados como resultado de los enfrentamientos entre las fuerzas del orden y presuntos criminales. Frente a esta práctica, diversas instituciones de defensa de los derechos humanos cuestionan las altas tasas de letalidad de los cuerpos policiales.

Aún en lo concerniente a la lucha contra la tortura y otros abusos semejantes, Brasil y Perú son signatarios de las principales convenciones internacionales sobre derechos humanos. Sin embargo, en ambos países es posible constatar innúmeras contradicciones e insuficiencias. En ese sentido, en Perú dejan mucho que desear las prácticas referidas a torturas practicadas por agentes del Estado - particularmente cuando los presuntos responsables son miembros del Ejército y de la Policía Nacional. Generalmente esas denuncias acaban siendo archivadas. 
Artigo original

Hegemonia - Revista Eletrônica do Programa de Mestrado em Direitos Humanos, Cidadania e Violência/Ciência Política do Centro Universitário Unieuro

ISSN: $1809-1261$

UNIEURO, Brasília, número 23, Janeiro a Junho de 2018, pp. 27-54.

Por otro lado, es pertinente ponderar que Brasil ratificó, en 1989, la Convención Internacional contra la Tortura. Entretanto, el Estado acabó siendo condenado por la Corte Interamericana de Derechos Humanos, por dejar pendiente el castigo a violaciones de derechos humanos cometidas durante el régimen autoritario (1964-1985). El asunto es complejo, principalmente por el desconocimiento de la Convención por parte del Supremo Tribunal Federal, al reconocer la validez de la Ley de Amnistía, aprobada en un contexto de represión, validando así el estatus de impunidad a los acusados de violaciones graves contra los derechos humanos, incluyendo crímenes como torturas, violaciones, desaparecimientos forzados y asesinatos.

Otro tópico que forma parte de la dignidad humana es, sin duda alguna, lo concerniente al trabajo análogo a la esclavitud, que aún existe en muchos países del continente y del mundo. En Brasil, la lucha contra el trabajo análoga a la esclavitud es otra de las facetas fundamentales de las políticas de protección de la dignidad humana y de los derechos civiles impulsadas. En 2005, el gobierno de Luiz Inácio Lula da Silva creó el Pacto Nacional para la Erradicación del Trabajo Esclavo. En consecuencia, la erradicación del trabajo en condiciones análogas a la esclavitud viene contribuyendo activamente a la liberación de trabajadores en esas condiciones. Así, en una década más de 40 mil trabajadores brasileños fueron rescatados de ese régimen, principalmente en la región Norte del país. Sea como fuere, en 16 de diciembre de 2016, la Corte Interamericana de Derechos Humanos dictó una paradigmática condena contra el Estado brasileño por tolerar, en pleno siglo XXI, la nefasta práctica de trabajo esclavo (MURILLO, 2016).

En Perú, aunque en menor número que Brasil, la trata de personas o la explotación de personas en la condición análoga a la esclavitud, no deja de ser relevante en términos proporcionales. En 2009, se registró que el mayor número de personas víctimas de este tipo de crímenes se concentraba en la explotación sexual y laboral. En 2014, el número de víctimas por explotación sexual llegó a 273 personas; mientras que la explotación laboral alcanzó la cifra de 61. En total entre, 2009 y 2014, fueron registrados 1,628 casos de víctimas de explotación sexual y 568 víctimas por explotación laboral. Generalmente las víctimas fueron mujeres y menores de 17 años. De las 2,287 denuncias sólo se han sentenciado hasta el día de hoy a 45 personas. Vale agregar que la subnotificación de este tipo de casos de afronta a la dignidad de la persona puede ser bastante alta en ambos países. 
Artigo original

Hegemonia - Revista Eletrônica do Programa de Mestrado em Direitos Humanos, Cidadania e Violência/Ciência Política do Centro Universitário Unieuro

ISSN: $1809-1261$

UNIEURO, Brasília, número 23, Janeiro a Junho de 2018, pp. 27-54.

En los dos países, los derechos civiles se encuentran expresados en la constitución respectiva de cada Estado. Diversas garantías buscan asegurar el ejercicio de derechos. Entre ellos se destacan mecanismos, procedimientos e instrumentos tales como: el habeas corpus, el mandato de seguridad - creación brasileña referente a la protección del ciudadano en la búsqueda de impugnar actos administrativos de las autoridades "manifiestamente inconstitucionales o ilegales", el babeas data, y la acción de inconstitucionalidad.

Para avanzar en el campo del acceso a la justicia y la promoción de los derechos humanos es importante ponderar sobre las contribuciones realizadas por los defensores públicos brasileños y peruanos. En Brasil, la Defensoría Pública busca garantizar la defensa de los segmentos sociales más vulnerables ante los tribunales. En Perú, esta función esta desdoblada en dos instituciones: la Defensa Pública Penal del Ministerio Público - que hace la función de su similar brasileño -; y el Defensor del Pueblo, entidad que busca supervisar el cumplimiento de los deberes de la administración estatal, así como la eficiente prestación de servicios públicos.

En lo concerniente a la dimensión de la Igualdad/Solidaridad, Brasil y Perú presentan resultados positivos. Sin embargo, los desafíos continúan siendo sumamente evidentes, urgentes y abrumadores. En términos operativos, esa dimensión procura verificar la efectividad de la implementación de medidas que contribuyan a disminuir las diferencias. También se busca aliviar la pobreza y promover los derechos sociales por medio de políticas públicas.

Ante ese desafío estructural, las políticas gubernamentales contribuyeron a disminuir estos índices negativos. El índice de Gini, indicador que mide la desigualdad de ingreso y, que varía de 0,0 (mínima concentración) a 1,0 (máxima concentración), muestra que la desigualdad en el Brasil se encuentra en constante caída desde 2003, llegando en 2015 a 0,491, el menor índice desde 1960. En Perú, según el Instituto Nacional de Estadística e Informática sugiere que, entre 2007 a 2016, el índice de Gini pasó de 0,500 a los 0,440 puntos. En otras palabras, hubo una reducción de la concentración de la riqueza. Evidentemente, se trata de una tendencia positiva, aunque también una reducción de la concentración poco expresiva en comparación con las altas tasas de crecimiento en el país - media de 6,8\% en los últimos años. De alguna forma, esa contradicción se ve reflejada en la baja expectativa de los peruanos con relación al devenir del país 
Artigo original

Hegemonia - Revista Eletrônica do Programa de Mestrado em Direitos Humanos, Cidadania e Violência/Ciência Política do Centro Universitário Unieuro

ISSN: $1809-1261$

UNIEURO, Brasília, número 23, Janeiro a Junho de 2018, pp. 27-54.

(LATINOBARÓMETRO, 2016). Sea como fuere, es importante registrar que la clase media peruana es cada vez más significativa en el marco de la estructura social del país. Actualmente, esa clase media peruana representa la mitad de la población del país andino. Algo semejante se puede observar en el caso de la clase media brasileña. Paralelamente, los indicadores de pobreza presentan una tendencia declinante en ambos países. Actualmente, la pobreza afecta aproximadamente $25-35 \%$ de la población brasileña y peruana.

Se infiere de lo expuesto que la evolución de la calidad de la democracia en Brasil y en Perú continuará dependiendo fuertemente da su correlación con los indicadores de las dimensiones de Libertades, de Igualdad, y también de Estado de Derecho. Lo hecho hasta ahora por diferentes administraciones brasileños ha sido significativo y relevante. En pocos años, ambos países han pasado a ser naciones predominantemente de clase media, dejando para atrás vergonzosos indicadores de desigualdad extrema. Entretanto, las conquistas socioeconómicas de los últimos años no están definitivamente aseguradas.

\section{Responsividad}

La Responsividad se define como la capacidad de satisfacer a los ciudadanos al implementar las políticas públicas en un sentido que atienda y/o corresponda a las demandas específicas de aquellos. En consecuencia, se procura auscultar las capacidades gubernamentales para satisfacer, por medio de las políticas públicas, a las principales demandas de la población, particularmente en términos de desarrollo social, gestión pública y deliberación política - todo ello, en medio de difíciles realidades presupuestarias y de otros recursos escasos. Así, la Responsividad - o capacidad de respuesta - es de gran importancia al momento de estudiar las configuraciones específicas en el campo de la representación, de las percepciones de legitimidad del Estado, y de la cultura política predominante.

Los estudios sobre Responsividad democrática son relativamente recientes en Brasil y Perú. La Responsividad presenta convergencias bastante evidentes con la Representación. Al mismo tiempo, esta dimensión demanda evaluar la evolución de la confianza entre gobernantes y gobernados. Se entiende, de partida, que las democracias de mayor calidad presentan altos y crecientes grados de Responsividad. Por tanto, en el 
Artigo original

Hegemonia - Revista Eletrônica do Programa de Mestrado em Direitos Humanos, Cidadania e Violência/Ciência Política do Centro Universitário Unieuro

ISSN: $1809-1261$

UNIEURO, Brasília, número 23, Janeiro a Junho de 2018, pp. 27-54.

estudio de la Responsividad es muy pertinente observar dos tópicos específicos de análisis e interpretación. De un lado, las percepciones de legitimidad del Estado, del gobierno, del titular del poder Ejecutivo, y del régimen político democrático. Y de otro lado, las capacidades de redistribuir recursos presupuestarios para atender a las demandas ciudadanas, en general, y a los grupos de presión y de interés, en particular.

Con relación a la Percepción de la legitimidad de la democracia es particularmente importante indagarse sobre el apoyo social al régimen democrático - en comparación con otras alternativas institucionales, básicamente de orientación autoritaria. El asunto es significativo ya que hasta en democracias consolidadas existen núcleos persistentes de opiniones negativas para con el régimen democrático. En Brasil, más de 70\% de los entrevistados se pronuncian a favor del régimen democrático. Entretanto, 17\% aceptaría un gobierno autoritario. En Perú, se presentan datos que generan cierta preocupación. Acontece que, desde 2014 a 2016, el porcentaje de peruanos que expresó apoyo al régimen democrático bajó del 71\% al 53\%, según la encuestadora GfK (2016). Inversamente, el apoyo a soluciones autoritarias es bastante consistente. Naturalmente, es necesario que los líderes políticos y de la sociedad civil continúen trabajando para reducir ese alto número de ciudadanos desinformados, indiferentes o sectarios, y atraerlos para el campo explícito a la democracia.

La confianza de los peruanos en sus instituciones presente niveles alarmantes, para un país que busca superar el retroceso autoritario de la década de los 1990. Es aún más alarmante cuando se constata que el $72 \%$ de la ciudadanía desaprueba la labor desempeñada por el Congreso y el 76\% desaprueba la labor del poder judicial. Al mismo tiempo, el Ejecutivo encabezado por el presidente Pedro Pablo Kuczynski viene consolidando, en la opinión pública, una tendencia de alta y creciente desaprobación, a pesar de tener pocos meses de gobierno.

Entre los factores que contribuyen a los bajos niveles de confianza en las instituciones democráticas del Perú se destacan: los efectos perniciosos del sistema de representación, el desarraigo de los partidos políticos, la poca efectividad de los controles institucionales en la gestión pública, la percepción negativa hacia los políticos y la política y, de forma indirecta, el papel de los medios de comunicación.

En Brasil, el grado de Percepción de la satisfacción y de la Confianza ciudadana con el desempeño de ciertas instituciones públicas y privadas (familia, vecindad, entidades 
Artigo original

Hegemonia - Revista Eletrônica do Programa de Mestrado em Direitos Humanos, Cidadania e Violência/Ciência Política do Centro Universitário Unieuro

ISSN: $1809-1261$

UNIEURO, Brasília, número 23, Janeiro a Junho de 2018, pp. 27-54.

gubernamentales, instituciones religiosas, medios de comunicación, policía, sistema político, entre otros) también es crucial en el estudio de la Responsividad democrática y de la legitimidad del gobierno. Según el así llamado Índice de Confianza Social, los brasileños confían fundamentalmente en sus familiares, y en instituciones como el cuerpo de bomberos, las Iglesias, y las fuerzas armadas (IBOPE, 2015). ${ }^{5}$

\section{Consideraciones Finales}

En una publicación reciente sobre la calidad de la democracia en 15 países latinoamericanos, Leonardo Morlino (2015) informaba, entre otras cosas, sobre el positivo desempeño de Brasil y de Perú en el plano regional. Efectivamente, los resultados agregados del Brasil arrojaban un alentador 3,68 puntos (en una escala 0,0 a 5,0). Ello colocaba a la democracia brasileña como la cuarta mejor calificada del subcontinente solamente superada por Chile, Costa Rica y Uruguay. Entretanto, el Perú (3,27) se ubicaba en el sexto lugar del mismo ranking (véase Cuadro 1).

\footnotetext{
${ }^{5}$ La segunda subdimensión que forma parte de la Responsividad tiene que ver con las limitaciones, tanto objetivas como subjetivas, especialmente en términos presupuestarios, político-administrativos e infraestructurales. Al respecto parece importante llevar en consideración, de un lado, la calidad de los políticos y su papel en el contexto del principio de la representación, dando atención especial a las necesidades, a las reivindicaciones de los ciudadanos y al desarrollo de la cultura política imperante. De otro lado, no es realista ignorar que las limitaciones presupuestarias acontecen en todos los países del mundo. Igualmente vale recordar que los gobernantes casi siempre demuestran interés en administrar recursos altos y crecientes.
} 
Artigo original

Hegemonia - Revista Eletrônica do Programa de Mestrado em Direitos Humanos, Cidadania e Violência/Ciência Política do Centro Universitário Unieuro

ISSN: $1809-1261$

UNIEURO, Brasília, número 23, Janeiro a Junho de 2018, pp. 27-54.

Cuadro 1: La Calidad de la Democracia en Brasil y Otros Países Latinoamericanos

\begin{tabular}{|l|l|l|l|l|l|l|l|l|l|}
\hline País & ED & RCE & RCII & PP & CP & R & L & S/I & Total \\
\hline Chile & 3,82 & 4,42 & 2,69 & 4,54 & 3,71 & 3,84 & 4,78 & 3,00 & 3,85 \\
\hline Costa Rica & 3,63 & 4,04 & 2,82 & 4,07 & 4,39 & 3,50 & 4,33 & 3,37 & 3,77 \\
\hline Uruguay & 3,44 & 3,74 & 2,74 & 4,75 & 4,07 & 3,84 & 4,78 & 2,65 & 3,75 \\
\hline Brasil & 2,50 & 4,86 & 3,40 & 4,23 & 4,28 & 3,16 & 4,17 & 2,85 & 3,68 \\
\hline Argentina & 2,27 & 3,75 & 4,34 & 4,17 & 3,93 & 3,26 & 4,17 & 3,09 & 3,62 \\
\hline Perú & 2,46 & 3,07 & 3,57 & 4,12 & 3,89 & 3,03 & 3,50 & 2,55 & 3,27 \\
\hline El Salvador & 2,19 & 3,77 & 3,45 & 3,53 & 3,67 & 2,98 & 3,98 & 2,44 & 3,25 \\
\hline Paraguay & 1,81 & 3,70 & 3,39 & 3,58 & 3,54 & 3,23 & 3,58 & 2,31 & 3,14 \\
\hline México & 2,37 & 3,47 & 3,25 & 3,44 & 3,68 & 2,78 & 3,11 & 2,99 & 3,14 \\
\hline Bolivia & 2,16 & 3,50 & 3,38 & 4,08 & 2,70 & 2,97 & 3,48 & 2,33 & 3,07 \\
\hline Guatemala & 2,37 & 3,86 & 2,27 & 3,30 & 3,92 & 2,94 & 3,37 & 2,13 & 3,02 \\
\hline Colombia & 1,77 & 3,10 & 4,33 & 2,66 & 3,54 & 3,07 & 3,22 & 2,31 & 3,00 \\
\hline Ecuador & 1,74 & 2,38 & 1,96 & 3,74 & 3,42 & 3,49 & 3,22 & 2,50 & 2,80 \\
\hline Venezuela & 0,92 & 1,85 & 3,67 & 2,91 & 2,74 & 3,19 & 2,00 & 3,10 & 2,55 \\
\hline Nicaragua & 1,70 & 1,15 & 3,49 & 3,07 & 2,62 & 2,86 & 2,21 & 2,41 & 2,47 \\
\hline
\end{tabular}

Fuente: Morlino (2015, p. 25). Incluye las ocho dimensiones de la calidad de la democracia:

Estado de Derecho (ED), Rendición de Cuentas Electoral (RCE), Rendición de Cuentas Interinstitucional (RCII), Participación Política (PP), Competencia Política (CP), Responsividad (R), Libertad (L), e Igualdad/Solidaridad (I/S).

Se infiere de lo anterior que, en el caso de Perú, la calidad de la democracia presenta indicadores razonables, especialmente, en lo concerniente a la Participación Política, a la Competencia Política, y a la Rendición de Cuentas Interinstitucional. Entretanto, es necesario continuar trabajando en lo concerniente a las otras dimensiones de la calidad de la democracia, principalmente en lo tocante al Estado de Derecho y a la Igualdad/Solidaridad. Es probable que Perú se mantenga en el subgrupo medio-alto del ranking desarrollado por Morlino. En todo caso, no deja de ser importante identificar cuáles son los puntos fuertes y vulnerables de la democracia peruana, con el propósito de ofrecer contribuciones para una agenda ampliada de trabajo. 
Artigo original

Hegemonia - Revista Eletrônica do Programa de Mestrado em Direitos Humanos, Cidadania e Violência/Ciência Política do Centro Universitário Unieuro

ISSN: $1809-1261$

UNIEURO, Brasília, número 23, Janeiro a Junho de 2018, pp. 27-54.

En el caso brasileño, a partir del - traumático - proceso de impedimento de la presidenta Rousseff, seguida de la polémica asunción del vicepresidente Michel Temer, es bastante probable que las evaluaciones sobre la calidad de la democracia sufran ajustes significativos. Desafortunadamente, en la opinión de los autores de este trabajo, los referidos ajustes no serán en un sentido positivo.

Por tanto, corresponderá a la ciudadanía y a los electores brasileños la última palabra sobre el acontecimiento en referencia. Trabajar por una reforma política integral que incluya una cláusula de barrera en el parlamento, la re-definición del distrito electoral para elecciones legislativas, mayores controles para el financiamiento de campañas, la reafirmación de la laicidad del Estado, la introducción de reformas específicamente electorales, y la profesionalización de los mecanismos de control y fiscalización - se adviene como una prioridad de la clase política y del conjunto de la sociedad brasileña, en los próximos meses (FLEISCHER, 2016).

9. Referencias Bibliográficas

AVRITZER, Leonardo. Impasses da Democracia no Brasil. Rio de Janeiro: Civilização Brasileira, 2016.

CARrion F., Julio, et al. Cultura Politica de la Democracia en Perú 2010: Consolidación Democrática en las Américas en Tiempos Difíciles. Lima: Instituto de Estudios Peruanos y Vanderbilt University, 2012.

D'ARAÚJO, Maria. Sobre Partidos e Qualidade da Democracia no Brasil, Desigualdade e Diversidade, Rio de Janeiro, v. 5, 217-238, jul. 2009.

DATASENADO. O Cidadão e o Senado Federal/Junho de 2016. Brasilia: Senado Federal, $2016 a$.

. Situação Política/Março de 2016. Brasilia: Senado Federal, 2016b.

FELD, Lars P.; VOIGT, Stefan. Economic growth and judicial independence: crosscountry evidence using a new set of indicators. European Journal of Political Economy, Cambridge, vol. 19, n. 3, 497-527, 2003. 
Artigo original

Hegemonia - Revista Eletrônica do Programa de Mestrado em Direitos Humanos, Cidadania e Violência/Ciência Política do Centro Universitário Unieuro

ISSN: $1809-1261$

UNIEURO, Brasília, número 23, Janeiro a Junho de 2018, pp. 27-54.

FLEISCHER, David. Attempts at Political Reform: (1985-2015) Still a 'Never Ending Story'. In XAVIER, Lídia; DOMÍNGUEZ, Carlos (org.). A Qualidade da Democracia no Brasil: Questões Teóricas e Metodológicas da Pesquisa. Curitiba: Crv, 2016. 87-140.

GFK. GfK Opinión febrero 2017 Encuesta Nacional Urbano Rural. Lima: GfK, 2017.

GGB. Assassinato de Homossexuais (LGBT) no Brasil: Relatório 2013/2014. Salvador: GCB, 2014.

IBOPE. Índice de Confiança Social 2015. Rio de Janeiro: IBOPE, 2015.

INEI. Informe Técnico sobre la Evolución de la Pobreza Monetaria 2009-2014. Lima: Inei, 2014.

IPSOS BRASIL. Sobre o Pulso Brasil. São Paulo: Ipsos, 2017.

LEVINE, Daniel; MOLINA, José. La Calidad de la Democracia en América Latina: una visión comparada. América Latina Hoy, Salamanca, n. 45, 17-46, 2007.

LATINOBARÓMETRO. Informe Latinobarómetro 2016. Buenos Aires: Corporación Latinobarómetro, 2016.

LIMONGI, Fernando; FIGUEIREDO, Argelina. Partidos políticos na Câmara dos Deputados: 1989-1994. Dados, Rio de Janeiro, v. 38, n. 3, 497-525, 1995.

MAINWARING, Scott. Sistemas partidários em novas democracias: o caso do Brasil. Rio de Janeiro: FGV, 2001.

; BEJARANO, Ana María; PIZARRO, Eduardo (eds.). La crisis de la representación democrática en los países andinos. Bogotá: Norma, 2008.

; SCULLY, Timothy R. Party Systems in Latin America. In MAINWARING, Scotty; SCULLY, Timothy R. (org.). Building Democratic Institutions: Party Systems in Latin America. Stanford: Stanford University Press, 1995. 1-34.

MORLINO, Leonardo. ¿Cómo analizar las calidades democráticas? In XAVIER, Lídia; DOMÍNGUEZ, Carlos (org.). A Qualidade da Democracia no Brasil: Questões Teóricas e Metodológicas da Pesquisa. Curitiba: Crv, 2016. 21-47.

. What qualities of democracy in Latin America? Mixing quantitative and qualitative analyses. In XAVIER, Lídia; DOMÍNGUEZ, Carlos (org.). Política, Cultura e Sociedade na América Latina: Estudos Interdisciplinares e Comparativos. Vol. 2, Curitiba: Crv, 2015. 17-51.

. Changes for Democracy: Actors, Structures, Processes. Oxford: Oxford University Press, 2011. 
Artigo original

Hegemonia - Revista Eletrônica do Programa de Mestrado em Direitos Humanos, Cidadania e Violência/Ciência Política do Centro Universitário Unieuro

ISSN: $1809-1261$

UNIEURO, Brasília, número 23, Janeiro a Junho de 2018, pp. 27-54.

MURILLO, Álvaro. Brasil recebe a primeira condenação da CIDH por escravidão. El País Brasil São Paulo, 16.12.2015, disponible

en:

http://brasilelpais.com/brasil/2016/12/16/intemacional/1481925647_304000.htmllrel=mas.

Consulta el 22 de diciembre de 2016.

O’DONNELL, Guillermo. Rendición de cuentas horizontal y nuevas poliarquías. Nueva Sociedad, Buenos Aires, n. 152, 143-167, 1997.

Democracia Delegativa? Novos Estudos Cebrap, São Paulo, v. 31, 25-40, 1991.

PUTNAM, Robert. Comunidade e democracia. Rio de Janeiro: Fundação Getúlio Vargas, 2005.

SCHEDLER, Andreas. ¿Qué es la rendición de cuentas? Cuadernos de transparencia, n. 3, México: Ifai, 2008.

. Conceptualizing Accountability. In SCHEDLER, Andreas; DIAMOND, LARRY;

PLATTNER, Marc F. (org.). The Self-Restraining State. Power and Accountability in New Democracies. Boulder: Lynne Rienner Publishers, 1999. 13-28.

SCHMITTER, Philippe C. The Ambiguous Virtues of Accountability. Journal of Democracy, Washington, v. 15, n. 4, 47-60, 2004.

TRANSPARENCY INTERNATIONAL. Corruption Perceptions Index 2016. Berlin: Transparency International, 2017. 